\title{
Maternidade e Identidade em Mulheres que Perderam Filhos: Aspectos Psicossociais
}

\author{
Eder Luiz Nogueira* \\ Adriano Roberto Afonso do Nascimento* \\ Universidade Federal de Minas Gerais, Minas Gerais, Brasil
}

\begin{abstract}
RESUMO
O objetivo dessa investigação foi compreender o processo de construção e de reconstrução da identidade, naqueles elementos relacionados à maternidade, de mulheres que perderam filhos. Foram entrevistadas sete mulheres com idades entre 39 e 56 anos, que perderam filhos/as por causas violentas ou acidentais. Dois procedimentos de análise foram utilizados: Análise de Conteúdo e Análise Fenomenológica Interpretativa. Foram identificadas nos relatos a percepção da maternidade ancorada em atributos tradicionais e a percepção da morte dos filhos como sem sentido. Na busca pela coerência para a memória e para a identidade, essas mulheres têm encontrado na saudade uma estratégia para o não esquecimento dos filhos em um contexto no qual se espera que a dor dessa perda seja vivida em silêncio.
\end{abstract}

Palavras-chave: identidade social; maternidade; atitude frente à morte; psicologia social.

\begin{abstract}
Motherhood and Identity in Women Who Lost Children: Psichosocial Aspects

This investigation aims at understanding the process of construction and reconstruction of identity in those elements related to motherhood, of women who lost their children. Seven 39-to-56-year-old women who have lost their children due to violent or accidental causes were interviewed. Two analysis procedures were used: Content Analysis and Interpretative Phenomenological Analysis. The perception of the motherhood connected to traditional attributes and the perception of the children's death as meaningless were identified in the reports. In the search of coherence for memory and identity, those women have found in remembrance and missing a strategy for not forgetting the children in a context in which it is expected that the pain of that loss is experienced in silence.

Keywords: social identity; motherhood, attitude to death; social psychology.
\end{abstract}

O objetivo da investigação na qual se baseia o relato aqui apresentado foi o de compreender, considerando-se os aspectos psicossociais envolvidos, o processo de construção e reconstrução da identidade, naqueles elementos relacionados à maternidade, de mulheres que perderam filhos. Apresentaremos, a seguir e como introdução, algumas informações sobre os significados sociais da maternidade e da morte. Após essa apresentação, serão identificadas as referências teóricas que nortearão a nossa análise de dados.

A maternidade tem sido tema de discussão para os mais diversos grupos sociais. Esse tema, tão amplo e controverso, também tem sido objeto de pesquisas em diferentes campos do conhecimento e estimulado discussões, por exemplo, em torno de políticas públicas relativas ao poder de decisão da mulher sobre a procriação.

Em seu conjunto, os argumentos utilizados na produção acadêmica sobre o tema oscilam entre a defesa da maternidade como determinada fortemente por componentes de natureza biológica, capazes de justificar em boa medida o comportamento e a afetividade da fêmea relativos às suas crias (Hrdy, 2001), e a maternidade como socialmente estabelecida e passível de mudanças históricas, sociais e culturais (Badinter, 1985; Paim, 1998).

\footnotetext{
Endereço para correspondência: Eder Luiz Nogueira - ederluiz@icb.ufmg.br

* Endereço para correspondência: Adriano Roberto Afonso do Nascimento - fgian@uol.com.br
} 
Considerando-se as investigações produzidas a partir dessa última referência, que admite a maternidade como construção social, variando de acordo com a época, os povos e a cultura, reconhece-se que, mesmo em um contexto de crescente diversificação das expectativas sociais relativas à condição feminina, a maternidade segue sendo considerada como uma componente importante da identidade de várias mulheres (Barbosa \& Rocha-Coutinho, 2007; Paim, 1998; Trindade \& Enuno, 2001), sendo por meio de diferentes processos que têm como princípio as crenças e valores compartilhados socialmente que as representações sobre o que é maternidade são incorporadas e vivenciadas como um dos fatores naturalmente relevantes para essa identidade (Trindade, 1991).

No Brasil, historicamente, a produção dessa naturalidade social/biológica se fez sentir mais acentuadamente a partir do século XIX, com a Proclamação da República, período em que ocorreram mudanças significativas no papel da mulher (Almeida, 1987; Neder, 2008; Rocha-Coutinho, 1994). Nesse momento, as relações sociais sofreram um processo de modernização e no bojo destas mudanças o lugar do feminino passou a ser definido a partir da referência ao doméstico, tendo a criança, aos poucos, ocupado o lugar de protagonista da experiência feminina/materna.

Segundo alguns autores, a manutenção dessas referências históricas no processo de construção social da maternidade nos sujeitos de uma determinada sociedade tem início durante a infância, período em que a criança, por meio de elaborações lúdicas, aprende a desempenhar os papéis representados pelos adultos e, geralmente, internaliza as referências de gênero características de seu contexto social (Azevedo, 2003; Brougère, 1995; Kishimoto \& Ono, 2008).

Nesse mesmo sentido, também muito precocemente as práticas discursivas sobre a maternidade desempenham importante influência na produção de configurações subjetivas nas mulheres. Segundo Rodrigues (2008),

[...] a maternidade está naturalmente inserida no ciclo de vida das fêmeas, mas provoca repercussão intensa na vida das mulheres como fenômeno social, porque tem uma dimensão simbólica, ideológica, religiosa, política e econômica e existe muito antes para elas, que enfrentam as alterações orgânicas e psíquicas da gravidez do que para a sociedade e o estado que absorverão mais tarde o novo cidadão (p. 44).
Como um dos produtos mais constantes desse processo de socialização feminino/materno, tem-se que a mãe, no Brasil atual, ainda tem sido apontada como a principal responsável, senão a única, pelo desenvolvimento esperado para a criança, em conformidade com os discursos científicos e culturais que adquiriram relevância junto à sociedade (Barros \& Trindade, 2007; Martins, 2008; Moreira \& Romagnoli, 2008; Rodrigues, 2008). Não obstante a existência de novos discursos que convocam o pai a assumir um papel de cuidado junto à criança (Osório, 2002), ainda predomina a cultura de um cuidado exclusivamente feminino sustentado, inclusive, pelas políticas públicas de saúde que desenvolvem programas voltados para os cuidados materno-infantis (Carranza, 1994; Galvão, 1999; Nascimento \& Rodrigues, 2003).

Segundo nosso entendimento, a consideração desse conjunto de aspectos históricos e psicossociais relativos à maternidade até aqui considerados é indispensável para o entendimento da experiência vivida por mulheres que perderam filhos.

É também com a intenção de situar de forma adequada o nosso tema de interesse, tema que será mais adiante circunscrito na apresentação dos objetivos específicos dessa investigação, que passamos a fornecer algumas informações sobre a morte e o morrer em nossa sociedade.

As representações simbólicas e sociais que norteiam o significado da morte e do morrer na modernidade e como foram historicamente construídas determinam os modos de expressão da dor da pessoa que perdeu um ente querido no contexto de uma dada sociedade. Certamente, estes significados e representações passam por variações culturais e se modificam de acordo com os grupos, podendo estas modificações acontecer nos limites de uma mesma sociedade.

Historicamente, em diversas sociedades ocidentais, a atitude humana diante da morte variou entre a percepção da morte como um evento público, acolhido socialmente e marcado por símbolos inscritos pela cultura, até a sua negação e deslocamento para os bastidores da vida social (Ariés, 1981). Tal deslocamento, resultado de uma nova sensibilidade diante da morte e do morrer que se configura nas sociedades ocidentais a partir da segunda metade do século XX, associa-se ao fato de que, segundo Ariès (2003) e Elias (2001), a morte na contemporaneidade sofreu um interdito. Como resultado desse interdito, já não se 
morre em casa, entre parentes, amigos e vizinhos, mas no hospital, em meio a instrumentos, aparelhos e medicamentos que objetivam garantir alguma sobrevida ao moribundo. Quanto aos que ficam, a morte de um ente querido poderá significar, para a pessoa que perdeu, uma experiência solitária a ser vivenciada distante do seu círculo social (Elias, 2001; Freire, 2006; Koury, 2003). Assim, as demonstrações de solidariedade limitam-se às formalidades dos cortejos fúnebres e quem perdeu viverá a experiência do luto de modo privado. O silêncio de sua dor é socialmente desejável, mas o sofrimento pela morte causa incômodo na rede e na cena social em que o enlutado se insere, não sendo conveniente a demonstração pública de que se está sofrendo.

Considerando-se que as atitudes e comportamentos frente à morte e ao morrer foram, ao longo do tempo, guiados por diferentes representações sociais (Freire, 2006), precisamos admitir que os significados atribuídos a esses objetos, bem como os modos de se vivenciar a perda, constituem experiências ao mesmo tempo pessoais e sociais.

Entretanto, para alguns autores, a experiência da morte de um ente querido é algo estritamente individual, podendo essa experiência ser vivida em fases ou estágios que variam desde a negação da morte até a sua aceitação e uma possível resolução do sofrimento relativo à perda (Bowby, 1990; Bromberg, 2000; Lindemann, 1994; Parkers, 1998). Assim, a dor sofrida por uma pessoa que perdeu um ente querido, conforme esta perspectiva, também poderá eventualmente se converter em patologia e essa pessoa, nesse caso, deverá se submeter a intervenções médicas e/ou psicoterapêuticas para encontrar soluções adequadas para a sua experiência. De forma geral, essas propostas acabam por individualizar o sofrimento relativo à perda $\mathrm{e}$ negligenciam ou consideram superficialmente os aspectos psicossociais envolvidos neste processo.

Investindo em outra direção, em estudo sobre o luto materno, Brice (1991) afirma que o sofrimento de uma mãe pela perda do filho pode ser entendido como formado por temas que se entrelaçam de uma maneira não linear ou distribuída em fases. Para este autor, a ausência do filho provocada pela morte é preenchida pelo sofrimento, e abandonar esta dor é tornar o filho definitivamente ausente e esquecido, negando a sua existência passada. Sobre esse mesmo aspecto, Martins (2001), ao estudar o discurso de mulheres que perderam filhos, afirma que as mães "negam-se a es- quecê-lo, a fazer de conta que não existiu, 'tocando a vida para frente"", e acrescenta "mais que 'pessoas que não sabem lidar com a perda', [essas mulheres] são verdadeiras 'guerreiras do sentido'. São também, seguramente, 'transgressoras do luto"” (p. 113). Ainda com relação ao luto e às lembranças dos filhos, Rangel (2008), em pesquisa na qual entrevistou pais e mães que perderam filhos, conclui que "as mães, mais que os pais, insistiram nas lembranças do filho morto e enfatizaram as perdas e pesares pelo relacionamento perdido" (p. 333).

Consideramos que o conjunto teórico por nós utilizado para o entendimento dos impactos causados pela perda de um filho para mulheres (Memória Social e Identidade Social) pode auxiliar na compreensão dessa vivência naquilo que ela tem de significado socialmente compartilhado, podendo contribuir assim para uma abordagem mais contextualizada da mesma.

A retomada dos estudos sobre a memória social, que se deu forma mais sistemática a partir dos anos 80 do Século XX, ao recuperar o caráter eminentemente social das recordações, mesmo daquelas consideradas individuais (Halbwachs, 1990), possibilitou um tratamento mais adequado dos processos sociais que possibilitam tanto a manutenção quanto o apagamento de elementos relativos ao passado dos grupos sociais. Ainda que haja especificidades e eventuais divergências no tratamento da memória social pelas diversas áreas das ciências humanas (Sá, 2005), pode-se considerar que todas elas partem do pressuposto de que "lembranças não são reflexões prontas do passado, mas reconstruções ecléticas, seletivas, baseadas em ações e percepções posteriores e em códigos que são constantemente alterados, através dos quais delineamos, simbolizamos e classificamos o mundo a nossa volta" (Lowenthal, 1998, p. 103).

Tais características, como já antecipamos, referem-se também às denominadas memórias pessoais, ou seja, as que dizem "respeito àqueles atos de recordação que tomam como objeto a história de vida de cada um. Falamos delas como memórias pessoais porque se localizam num passado pessoal e a ele se referem" (Connerton, 1999, p. 25). Pode-se considerar que, mais especificamente, as memórias pessoais seguem, na sua construção e na sua manutenção, os mesmos princípios admitidos para as memórias sociais: coerência entre elementos recordados e entre esses e suas respectivas avaliações; veiculação através da comunicação cotidiana, o que possibilita, no presente, a ma- 
nutenção e a atualização das recordações e; associação a sentimentos que particularizam o conteúdo recordado (Nascimento \& Barra, 2010). Este último princípio, particularmente importante para o presente trabalho, toma corpo no que chamamos de nostalgia.

A nostalgia, tradicionalmente avaliada como negativa e vinculada ao imobilismo e à fixação no passado (McCann, 1941; Ritivoi, 2002; Starobinski, 1966), tem recentemente sido reconhecida como emoção capaz de possibilitar ao nostálgico um aumento de autoestima, uma melhora na percepção de vínculos sociais e um sentido existencial mais positivo (Wildschut, Sedikides, Arndt \& Routledge, 2006; Routledge et al., 2011; Zhou, Sedikides, Wildschut \& Gao, 2008; Sedikides, Wildschut, Arndt \& Routledge, 2008). Nos países de língua portuguesa, é comum, no cotidiano, considerarmos a saudade como termo e sentimento equivalente à nostalgia. Nesse sentido, em trabalho que procura demonstrar a importância da consideração da articulação entre saudade e memória social para a análise psicossocial de recordações, Nascimento e Menandro (2005) caracterizam a saudade como a "percepção individual de privacidade das lembranças aliada à partilha social do sentimento" (p. 16).

Um quarto princípio recorrente na produção acadêmica sobre memória social é a admissão de que esta se liga de forma direta à identidade (Candau, 2001; Fentress \& Wickham, 1992; Jelin, 2001; Laurens, 2002; Olick \& Robbins, 1998; Pollak, 1992). Como reconhece Connerton (1999), "manifestações da memória figuram significativamente nas descrições que fazemos de nós próprios, porque a nossa história passada é uma fonte importante da ideia que fazemos de nós próprios" (p. 25).

No presente trabalho, para o tratamento da categoria identidade, nos baseamos na Teoria da Identidade Social (Deschamps \& Moliner, 2009; Torres \& Camino, 2011; Worchel \& Coutant, 2004).

Segundo Tajfel (1983), a identidade social é a "parcela do autoconceito de um indivíduo que deriva do seu conhecimento da sua pertença a um grupo (ou grupos) social, juntamente com o significado emocional e de valor associado àquela pertença" (p. 290). Nessa definição podem ser identificados os três elementos que compõem a identidade: o cognitivo ("conhecimento de sua pertença"), o avaliativo ("valor associado àquela pertença") e o emocional ("significado emocional").
Três processos inter-relacionados dão suporte à Identidade Social: Categorização Social, Comparação Social e Diferenciação Social. A Categorização Social é o agrupamento de indivíduos considerando-se critérios entendidos como socialmente relevantes para uma sociedade. Tal agrupamento é possibilitado e reiterado pela Comparação Social e pela Diferenciação Social, que permitem, através do contraste entre características sociais, a identificação do próprio grupo (nós, ingroup) e do(s) outro(s) grupo(s) (eles, out-group) (Tajfel, 1983).

Partindo desse conjunto mais geral de elementos diretamente vinculados ao entendimento das relações intergrupos, alguns estudos posteriores, particularmente aqueles realizados pelo que se convencionou chamar de Escola de Genebra (Amâncio, 2004), têm demonstrado que a formação da própria identidade pessoal segue as diretrizes fornecidas pelas relações intergrupos consideradas como significativas por uma dada sociedade em um dado momento (Deschamps \& Moliner, 2009).

Reconhecendo a configuração hierarquicamente assimétrica da sociedade, esses estudos têm demonstrado que, por exemplo, homens e mulheres se pensam e se comportam, quando em situações nas quais as referências intergrupo e intragrupo se mostram relevantes, considerando como atributos pessoais elementos que são claramente determinados por essa configuração assimétrica (Amâncio, 1994; Lorenzi-Cioldi, 2002 e 2003).

Nesse ponto, é adequado reconhecer que os elementos disponíveis para a construção de referências identitárias, também em um contexto de relações assimétricas, são justamente aqueles disponíveis no acervo mais abrangente das memórias sociais.

Com base no que foi discutido até agora, apresentaremos os objetivos e os procedimentos de coleta e análise de dados desta pesquisa.

Objetivo Geral: identificar e analisar os processos psicossociais relativos à mudança e à permanência da identidade e do significado da maternidade em mulheres que perderam filhos.

Objetivos específicos: 1) Caracterização pessoal das entrevistadas, considerando-se estado civil, número de filhos, idade, ocupação, religião, tempo do falecimento do filho ou filha e motivo do falecimento; 2) Identificar e descrever os significados atribuídos pelas 
entrevistadas à maternidade; 3) Identificar e descrever os significados atribuídos pelas entrevistadas à morte; 4) identificar e descrever como as lembranças do filho ou filha que morreu se associam aos significados que as entrevistadas atribuem à maternidade e à morte e as estratégias utilizadas por essas mesmas entrevistadas para o lidar com essa perda.

\section{MÉTODO}

\section{Sujeitos}

Foram entrevistadas sete mulheres com idades que variaram de 39 a 56 anos, residentes na Região Metropolitana de Belo Horizonte/MG, que perderam filhos/as por causas violentas (4 homicídios) ou acidentais ( 2 acidentes de trânsito e 1 afogamento), cujo tempo decorrido da morte do/a filho/a até o momento da entrevista fosse superior a seis meses e não ultrapassasse três anos. As entrevistadas apresentaram níveis de escolaridade que variaram desde a educação básica incompleta (5 entrevistadas) até a pós-graduação (2 entrevistadas). A idade em que o filho morreu não foi considerada como critério para participar da pesquisa, porém constatamos que todos eram jovens ou muito jovens (idades entre 3 e 32 anos). Quanto ao estado civil, 5 se declararam casadas ou vivendo em união estável, uma declarou-se desquitada e uma última é viúva. O número atual de filhos variou de um a quatro.

\section{Instrumentos}

Foram realizadas entrevistas guiadas por um roteiro semiestruturado que contemplou um conjunto de temas relacionados aos significados da maternidade e da morte, às características dos filhos que morreram e aos modos de lidar com as repercussões que se apresentaram após a perda. A utilização de roteiro semiestruturado é bastante comum em investigações qualitativas, mesmo naquelas, que, segundo Smith e Eatough (2010), utilizarão o método fenomenológico para a análise de dados. Todas as entrevistadas assinaram o Termo de Consentimento Livre e Esclarecido aprovado pelo COEP/UFMG (Parecer $\mathrm{n}^{\circ}$ 0003.0.216.203 - 10).

\section{Procedimentos}

A coleta dos dados aconteceu entre os meses de setembro de 2010 e maio de 2011 e o tempo das entrevistas variou entre 51 minutos e três horas e quinze minutos. Todas as entrevistas foram gravadas e transcritas integralmente. $\mathrm{O}$ dia, o local e a hora dos encontros para a realização das entrevistas foram escolhidos pelas participantes. Para a análise das entrevistas, utilizamos um procedimento que procurou associar a técnica de análise qualitativa de conteúdo (Bardin, 1979; Franco, 2003) às estapas analíticas da Análise Fenomenológica Interpretativa (Smith \& Eatough, 2010), com o objetivo de identificar "os 'significados psicológicos' ou as 'constituintes de significados' [...] reveladores da 'Estrutura' do fenômeno vivido" (Trindade, Menandro, \& Gianordoli-Nascimento, 2007, p. 78) pelas entrevistadas. Nesse sentido, não realizamos, a rigor, uma análise fenomenológica, tal qual preconizada, por exemplo, por Giorgi (2008). Assim, de forma mais objetiva, utilizamos as proposições de Bullington e Karlsson (1984), Smith e Eatough (2010) e Giorgi (2008) como guias para o procedimento de análise qualitativa de dados em psicologia, considerando a proposta desenvolvida por Trindade (1991), sem, entretanto, nos guiarmos exclusivamente pelos pressupostos da fenomenologia de Husserl. Consideramos que, mais do que uma "descontextualização" do método fenomenológico, essa opção permite extender a sua contribuição para outros procedimentos de análise qualitativa, permitindo, particularmente ao pesquisador que possui outras referências teóricas de base, avançar na compreensão dos processos de construção de significados (Gomes, 1998; Trindade et al., 2007; Smith \& Eatough, 2010).

Descreveremos agora, de forma detalhada, como realizamos as 5 fases da análise dos dados.

Fase 1: Leitura preliminar dirigida pela procura por unidades de significado, segundo os objetivos propostos pela investigação. Procuramos nos ater, nessa fase, à identificação e delimitação de trechos de relatos que apresentaram algum grau de "independência" quanto ao significado e que, portanto, poderiam ser considerados como unidades. Buscamos reter sobretudo aquilo que foi dito pelas entrevistadas, evitando uma leitura guiada por pressupostos teóricos ou pelas nossas próprias crenças sobre o tema de interesse. Em comparação com a Análise Qualitativa de Coteúdo, é conveniente esclarecer que, como o objetivo dessa fase não era produzir um conjunto homogêneo de categorias, não buscamos regularidas na fala das entrevistadas, bem como não definimos a priori qualquer unidade de registro (palavra, frase, parágrafo ou tema). 
Fase 2: Reorganização dos relatos segundo o tema das unidades de significado identificadas na primeira fase. Esse procedimento de reorganização baseou-se de forma mais evidente na técnica de Análise de Conteúdo, privilegiando, em um primeiro momento, o agrupamento de unidades mais claramente próximas quanto ao significado até que, progressivamente, chegássemos a um agrupamento mais complexo que pudesse ser admitido como o entendimento do tema de interesse para cada uma das entrevistadas. Guiamo-nos, nesse processo, pela "variação imaginária", tal qual sugerida por Bullington e Karlsson (1984) e Giorgi (2008), para a apreensão da essência de um determinado fenômeno. Como nossa intenção era produzir uma estrutura para cada uma das entrevistas, a "variação imaginária" norteou a própria reorganização dos temas, possibilitando, pelo contraste entre as unidades de significação, uma forma rigorosa de delimitação desses temas.

Fase 3: Padronização parcial da linguagem (da fala literal ao foco na experiência). Trata-se aqui de um momento no qual os trechos reagrupados na fase anterior foram integrados em um primeiro relato produzido pelos pesquisadores. Conforme Smith e Eatough (2010), "o objetivo é fornecer uma leitura textual rigorosa do relato do participante, transitando entre a descrição e os diferentes níveis de interpretação e, em todos os casos, diferenciando as palavras do participante da análise do pesquisador" (p. 336, destaques no original).

Fase 4: Elaboração do relato que privilegia a relação entre as unidaes de significado, segundo a vivência do sujeito. Pretende-se chegar, nessa fase, a uma estrutura que integre, de forma articulada, os conjuntos de unidades de significação identificados e que possibilite, por fim, a proposição de um quadro mais abrangente da experiência do sujeito relativa a determinado fenômeno (Bullington \& Karlsson, 1984; Giorgi, 2008; Trindade et al., 2007). Convém esclarecer que cada uma das entrevistas gerou uma estrutura autônoma, produzida a partir dos itens bastante gerais propostos no roteiro de entrevista e pelos acréscimos feitos pelas entrevistadas a esse roteiro.

Fase 5: Por fim, essas estruturas individuais foram comparadas buscando-se significados compartilhados e individuais com o objetivo de compreender, de forma mais apurada, as possíveis constâncias e variações na experiência do grupo de entrevistadas. Segundo Giorgi (2007),
[...] é provável que uma pesquisa comportando vários sujeitos dê origem a diversas estruturas típicas, mas do que [a] uma única. [...] por preocupação de simplicidade, um pesquisador deveria sempre tentar delimitar uma única estrutura (síntese) para o conjunto dos sujeitos da pesquisa. (p. 401)

Nessa fase, utilizamos a análise qualitativa de conteúdo para a comparação entre as estruturas. Assim, os relatos elaborados na fase 4 foram tratados como um novo corpus textual, procedendo-se à codificação e à categorização dos trechos dos relatos segundo a sua proximidade de conteúdo. Como resultado dessa fase obtivemos uma estrutura geral (síntese) que, só então, foi submetida a uma leitura teórica.

\section{RESULTADOS}

Dada a característica do método de análise utilizado e a necessária concisão desse relato, apresentaremos os resultados obtidos já organizados segundo as referências compartilhadas (estrutura geral). Com a finalidade de manter o sigilo, as entrevistadas serão apresentadas com nomes fictícios.

\section{A Maternidade}

As mães entrevistadas compartilham concepções e avaliações tradicionais com relação à maternidade. Proporcionar segurança, proteção contra a violência, promover a saúde, educá-los e conduzir a vida escolar foram as principais características que as entrevistadas apontaram como atribuições de uma mãe responsável, amorosa e que cuida dos filhos: "o que acontece, qualquer coisinha que acontece a gente está correndo, a gente está preocupada" (Márcia); "As responsabilidades da mãe é criar, educar, fazer deles [os filhos] um homem ou uma mulher. Ensinar que não pode andar no caminho errado, mostrar outro caminho [que não seja o errado]" (Adriana).

Em acréscimo, Márcia, Lúcia, Marisa, Adriana e Eliane definiram as atribuições relativas à atenção, cuidados e responsabilidades com os filhos de acordo com o gênero parental. Para elas, mãe e pai têm papéis diferentes na relação com os filhos. Lúcia, por exemplo, vincula o papel do pai ao rigor na disciplina dos filhos e sugere que, em função da ausência do pai, "talvez eu não tenha conseguido exercer minha maternidade na plenitude porque eu tive que ser pai. Eu fico pensando que eu poderia ter sido mais afetuosa, mais carinhosa, mais de dar colo. Eu hoje olho pra 
trás e vejo que eu fui um pouco racional, de fazer papel mais de provedora, de pai" (Lúcia).

As mães entrevistadas destacaram que a mulher é bem mais próxima dos filhos e mantém para si responsabilidades que o pai não tem condições de assumir, seja em função do trabalho, pelo fato de permanecer um período muito longo fora do lar, ou por não possuir o manejo adequado para o cuidado com crianças. Esse manejo adequado é reconhecido explicitamente por uma das entrevistadas como vinculado diretamente à natural condição feminina/materna: "Acho que é a plenitude da mulher. Ser mãe inclui não só o nascimento em si, mas gerar. Como feminina, eu me realizei quando fui mãe" (Mariana).

Como pudemos observar, para as mulheres entrevistadas, a maternidade e a maternagem estão intimamente associadas à identidade feminina. Ser mãe e se responsabilizar convenientemente pelos filhos constitui para elas uma realidade capaz de completar a feminilidade. A mãe, segundo as entrevistadas, é quem dá afeto, estrutura as relações familiares e protege os filhos. A mulher deve inclusive, pelo que as mães narraram, suprir a eventual ausência do pai, agregando às suas funções as atribuições do pai ausente ou sobrecarregado de tarefas fora do lar.

\section{A morte}

As mães entrevistadas compartilham de sentimentos comuns sobre o que é a morte e sobre o que as outras pessoas pensam sobre ela. As narrativas foram marcadas pela impossibilidade de se definir a morte e encontrar um significado único para a sua ocorrência, principalmente nos casos da morte súbita em que não é concedida às pessoas qualquer preparação para a perda. Definir a morte é um desafio. Grande parte das mães recorreu à religião para dar um sentido à perda. Somente Mariana se refugiou na razão científica para explicar a morte, mas argumenta tacitamente que os modos sociais de produzir a vida não se adequaram à realidade da natureza. Para elas, o mais absurdo é a morte do filho anteceder a dos pais.

Para Márcia, a morte foi ingrata, não respeitou os projetos da filha, nem sua idade, pois era muito nova. Além disso, a morte levou-lhe a filha tão amada, de cuja vida compartilhou intensamente, não somente como mãe e filha, mas como amigas: "Leva a menina com vinte e dois anos" (Márcia). Mas consola-se ao pensar que Deus quer as pessoas boas ao seu lado e a filha era boa. De um modo próximo a este pensamento, Marisa pensa que só os bons morrem: "Porque que os bons morrem... Só os bons" (Marisa), porém, não acredita que a morte do filho foi da vontade de Deus, pois os casos de assassinato são contrários a ela.

Márcia, não sem aflição, acredita que a morte da filha também serviu para livrá-la de experiências ruins. Ela pensa que a morte evitou que a filha se cassasse com uma pessoa de índole ruim, o que traria sofrimento para a filha e, também, para ela: "Deus fez o melhor pra ela, entendeu? Porque ela era muito boa... pra pessoa cair na mão de coisa errada, creio que Deus fez o melhor pra ela, fez o melhor pra mim" (Márcia). Lúcia, assim como Márcia, pensa que a morte do filho serviu para livrá-lo de um sofrimento maior, um acontecimento que a protegeu como mãe. Esta fala demonstra certa resignação e uma busca de compreensão. Ainda que com contradições, a morte do filho ofereceu-lhe um sentido, pois neste caso é compreensível que ocorra antes da morte da mãe: " $E u$ tinha uma preocupação enorme com o futuro do meu filho e um medo muito grande de vê-lo sofrer, de não poder ajudá-lo [...]. Tem hora que me bate a ideia de que poderia ser um livramento de vê-lo sofrer. Não sei, pode ser bobeira, loucura, mas eu sei que isso facilita as coisas pra mim. Mas é a certeza de uma certa preservação, como se eu tivesse aliviada, não que ele merecesse isso, não é isso. Mas é como se o fato dele não sofrer me desse um alivio e eu poder encarar a morte de frente, vê-la de uma outra forma" (Luiza). Este sentimento de que foi poupada a ajuda a conviver com a morte do filho. Trata-se de uma contradição angustiante, ao mesmo tempo em que se tenta criar um sentido para a morte do filho, depara-se com uma elaboração que gera outro mal-estar, o de que privar-se da companhia do filho por causa da morte foi uma solução para um possível sofrimento materno.

Mariana, ao contrário de Márcia e Luzia, pensa que a morte dos filhos em hipótese alguma deveria anteceder a das mães: "O grande problema na minha vida então é esse: ela não ter uma ordem para acontecer. Abrupta, de uma hora pra outra" (Mariana).

Para Marisa, Adriana, Eliane e Sônia, aceitar a morte como aconteceu com os filhos é impossível, pois foram assassinados. Quando uma pessoa está doente, a morte é uma possibilidade, mas no caso dos filhos, que estavam sadios, é motivo para enorme transtorno: "Acho que a morte tinha que vir quando 
Ele [Deus] levasse, quando uma enfermidade que não tivesse cura ou então de velhice, mas não que os outros matem, eu não aceito" (Marisa); "Porque que se a pessoa morre quando está doente, a gente vai se preparando para aquilo... para perder aquela pessoa, mas quando morre dessa forma... [Meu filho] tinha tantos sonhos" (Adriana); "Eu acho assim, que [a morte] é da natureza, que a gente cresce, cada um tem a sua hora. Mas igual ele foi é que está difícil de entender. Aqui na minha cabeça eu fico perguntando, dia e noite, por que o menino foi embora?" (Eliane); "Foi uma morte que eu fico ali pensando: 'Meu Deus! O homem tirar a vida do próprio homem'. Eu não conformo com isso, não conformo..." (Sônia). A sensação de que poderiam ter evitado a morte causa-lhes culpa e indignação, pois não lhes foi possível proteger os filhos dos assassinos.

O momento da notícia da morte do filho foi relatado por elas como o mais difícil, angustiante e impactante de suas vidas. À exceção de Mariana, que estava presente no local em que o filho morreu, e de Sônia, que recebeu a notícia no trabalho pelos vizinhos, as mães foram informadas do que ocorreu com os filhos por telefone: "Quando cheguei ao portão perto de casa, o telefone tocou, era meu esposo que falou comigo que eu não preocupasse, mas que pegasse o ônibus e voltasse porque tinha tido um acidente com ela" (Márcia); "O telefone toca, era a notícia [...] e eu que atendi. Pegou-me de surpresa [...] quem está falando aqui é o pai de fulano, os meninos sofreram um acidente e o seu filho machucou muito" (Luiza); "O telefone tocou... ai falou assim: o seu filho morreu... Falei [assustada]: O quê? Aí, eu comecei a tremer, passei o telefone pra namorada [do filho]. Nisso eu não aguentei nem atender ao telefone, ela [a nora] acabou de atender" (Marisa). Ao relatarem o modo como receberem as notícias, as mães se emocionam. Foi um momento de expectativa e angústia. Márcia e Eliane contam que pensaram em um acidente com menores proporções do que realmente havia acontecido, que encontrariam os filhos já em recuperação ao chegarem ao hospital. Lúcia, porém, sentiu desde o momento em que recebeu a ligação que o filho havia morrido. O modo como as mães foram comunicadas da situação adversa ocorrida com os filhos revela despreparo das pessoas que ligaram para avisar. Uma das mães encontrava-se sozinha, saindo do trabalho, no momento que recebeu a ligação telefônica, o que ocasionou um nível alto de ansiedade e expectativa com relação à vida do filho.
As mães narram que no momento em que a notícia de que o filho havia morrido se tornou uma verdade incontestável, sentiram-se fustigadas pela dor física e moral. Exauridas de forças, Mariana e Mariza contam que a dor ao constatar que o filho estava morto foi como se estivessem em "processo de parto". As demais mães sentiram que não tinham mais chão, como se lhes faltasse apoio.

\section{Características do filho}

As mães entrevistadas destacaram características positivas dos filhos tanto na relação com elas, como com a família ou na vida social. O carinho dedicado por seus filhos a elas foi relatado em todas as narrativas e uma delas destaca que a filha, além de ajudá-la nos serviços domésticos e a cuidar dos outros filhos, destinava parte do seu salário para o orçamento familiar: "Era uma moça que me ajudava em tudo, dentro de casa com os irmãos, desde pequena olhava os irmãos. Tanto que ela tava trabalhando e estava afastada da empresa, recebendo o seguro desemprego. Aí, ela arrumou serviço pra não ficar parada, pra me ajudar... 'Eu vou trabalhar pra te ajudar"' (Márcia). Outras três mães disseram também que os filhos contribuíam com o pagamento das despesas da casa.

Os adjetivos usados para a descrição dos filhos reforçam as virtudes maternas, pois, segundo as mães entrevistadas, educar os filhos e ensiná-los a conduzir a própria vida é tarefa da mãe. Nesse sentido, as mães procuraram destacar que os filhos possuíam atributos socialmente esperados, o que reflete a educação que receberam no lar, em especial, delas. As mães que tiveram os filhos assassinados se esforçam para resgatar a imagem deles como pessoas que foram inocentes e frágeis com relação ao evento que os vitimou. Para elas, é inconcebível que o filho tenha sido assassinado devido a algum comportamento inadequado, como, por exemplo, envolvimento com o tráfico de drogas, participação em roubo ou brigas provocadas por eles: "Depois, ele saiu [da cadeia], mas não praticou mais esse ato. Graças a Deus, ficou trabalhando. Não voltou [a cometer delitos], ficou trabalhando e, de repente, com pouco tempo, aconteceu isso com ele." (Sônia).

\section{As lembranças e a saudade}

A lembrança dos filhos que morreram permaneceu na consciência das mães entrevistadas como uma vivência de maternidade que não cessou. A morte não 
dissolveu estes vínculos, as recordações são narradas, muitas vezes, como se eles ainda estivessem vivos.

Para algumas delas, a crença na existência do espírito após a morte consola e sugere a possibilidade de que um dia poderão reencontrá-los. Este foi o caso de Lúcia, que buscou a ajuda de uma senhora espírita: "Hoje eu enxergo esta senhora como um elo de ligação entre mim e o meu filho" (Lúcia). Eliane não buscou consolo no espiritismo, mas também acredita que o filho sobreviveu à morte e um dia irá reencontrá-lo: "Eu estou esperando que eu vou encontrar com ele lá em cima" (Eliane).

Conservar objetos e imagens que preservam a memória dos filhos também foi uma atitude importante para algumas mães, pois esses objetos e imagens representam homenagens póstumas, aliviam a dor da falta e garantem que eles jamais serão esquecidos. Márcia mantém a foto da filha como plano de fundo do computador que foi comprado pela filha morta. Mariana e Eliana também se sentem bem preservando a memória dos filhos por estes meios: "Tem um cofre que a gente guarda as nossas riquezas. Então, é o sapatinho que ele andava direto, o passaporte que ele tinha tirado, que a gente ia viajar pra Disney, os desenhos dele. O dia que eu mudei pra esse apartamento, a primeira coisa que eu fiz foi arrumar o guardaroupas do meu primeiro filho, a segunda coisa que eu fiz foi arrumar o guarda-roupas do meu filho que morreu" (Mariana); "Eu vou no quarto, olho as fotos que eu mandei fazer, [leio] uns dizeres de quando fez a missa. $O$ retrato de quando ele era bebê toda vida ficou na parede, não tirei e agora depois que ele morreu eu fiz uns dizeres, até muito bonito, eu coloquei no porta-retrato que fica na beirada da minha cama" (Adriana).

Algumas mães relataram que as lembranças e a saudade associada a elas são vividas silenciosamente. Eliane e Sônia disseram que preferem não compartilhar com a família as lembranças dos filhos, mesmo que sejam boas, pois temem que possam provocar sofrimento e, por isso, escolheram mantê-las consigo para conservar a imagem pública de que a perda foi superada: "Eles não querem que eu fico lembrando. Ninguém toca no assunto. Eu preferi engolir o choro. No trabalho, eu chorei muito, chorava bastante, dentro do ônibus. Dentro de casa, eu engolia." (Eliane); "Eu sempre mentindo para não ver eles sofrerem. Nunca lembrar para eles esquecerem, para não ter a lembrança, esquecer, evitar de falar." (Sônia).

\section{DISCUSSÃO}

As mães entrevistadas apresentaram narrativas que expressaram conceitos e avaliações tradicionais com relação à maternidade e aos cuidados com os filhos (Martins, 2008; Rocha-Coutinho, 1994; Trindade, 1991; Trindade \& Enumo, 2002). Educar, proteger e cuidar foram atributos identificados como característicos da maternidade, independente do nível de escolaridade e da idade das entrevistadas. Reconhecendo o desempenho quase sempre adequado dessa função, essas mulheres assumiram a importância dessa referência identitária socialmente compartilhada, com seus elementos cognitivo, avaliativo e emocional, na construção da própria identidade pessoal, assumindo, com isso, a responsabilidade pessoal que ela traz (Deschamps \& Moliner, 2009). A admissão dessa responsabilidade é, por exemplo, um dos elementos centrais a guiarem a avaliação que as entrevistadas fizeram dos próprios filhos. Conforme o relato das caraterísticas dos filhos falecidos, foi possível observarmos elementos referentes a uma estratégia de busca pela coerência entre a percepção do cuidado adequado na criação dos mesmos e o seu resultado, ou seja, a avaliação sobretudo positiva que possuem dos filhos. Destacamos aqui que não se trata necessariamente de uma positivação irrealista, como muitas vezes se considera, mas da manutenção da positividade que é própria dos processos identitários (Tajfel, 1983).

Nesse sentido, entrelaçaram-se, nessa busca por coerência, recordações sobre a relação entre as mães e seus filhos, na composição de um quadro no qual a morte destes foi entendida como algo que, em quase todos os casos, ainda procura significação. Mesmo para as mães que já atribuíram algum significado ao acontecimento (autoproteção ou o fato de "só morrerem os bons"), tal significado é necessariamente provisório, pois a memória e a identidade são processos que necessitam de constante atualização, inclusive nas práticas comunicativas (Deschamps \& Moliner, 2009; Fentress \& Wickham, 1992; Halbwachs, 1990).

Quanto a essas práticas, pôde-se perceber que, mesmo que a construção dessa necessária coerência acima referida devesse ser buscada nos círculos sociais mais próximos, as mães entrevistadas reconheceram não se sentirem autorizadas a tornarem pública, enquanto não diluída, a dor da perda, para além do momento no qual a morte ocorreu (Elias, 2001; Freire, 2006; Koury, 2003). 
Ainda que em silêncio, as mães indicaram a necessidade de continuar enfrentando a morte dos filhos e sobreviver a ela, pois não querem esquecê-los ou deixar que sejam esquecidos. Podemos considerar que se trata de um equilíbrio difícil, pois ainda continuam a ser mães de outros filhos e precisam, como boas mães, garantir a sua proteção ("eu sempre mentindo para não ver eles sofrerem"), e, ao mesmo tempo, negam-se a esquecer os filhos mortos, mantendo-os vivos na saudade.

A recordação saudosa dos filhos mortos é, para essas mães, um sentimento agridoce (Nascimento \& Menandro, 2005), como é característico da saudade, que mistura a tristeza da perda às recordações delicadamente guardadas dos momentos felizes que viveram juntos. Nas vivências dessas mulheres, a saudade é a possibilidade de articulação concreta da memória e da identidade (Laurens, 2002). Memória que se espalha e se ancora no seu cotidiano, como nas fotos e sapatos "guardados como tesouros". Identidade que possibilita que continuem em frente, pelos outros filhos.

Para concluir, devemos admitir que, em nosso estudo, o tempo da perda foi considerado somente com a finalidade de estabelecermos critérios para inclusão dos sujeitos. Contudo, seria importante que outros estudos fossem realizados com o propósito de conhecer, por exemplo, quais seriam os elementos, se é que eles existem, associados ao tempo de perda do filho na vivência materna.

\section{REFERÊNCIAS}

Almeida, A. M. (1987). Introdução. In A. M. Almeida (Org.), Pensando a Família no Brasil: Da Colônia à Modernidade (pp. 13-21). Rio de Janeiro: Espaço e Tempo, EdUFRRJ.

Amâncio, L. (1994). Masculino e Feminino. A construção social da diferença. Porto: Afrontamento.

Amâncio, L. (2004). Identidade Social e Relações Intergrupais. In J. Vala, \& M. B. Monteiro (Orgs.), Psicologia Social (6 $6^{\mathrm{a}}$ ed.) (pp. 387-400). Lisboa: Fundação Calouste Gulbenkian.

Ariès, P. (1981) História social da criança e da família (2 $2^{\mathrm{a}}$ ed.) (D. Flaksman, Trans.). Rio de Janeiro: Livros Técnicos e Científicos.

Ariès, P. (2003). História da morte no ocidente (P. V. Siqueira, Trans.). Rio de Janeiro: Ediouro.

Azevedo, T. M. C. (2003). Brinquedos e gênero na educação infantil - um estudo do tipo etnográfico no estado do Rio de Janeiro (Tese de Doutorado). Universidade de São Paulo, São Paulo.

Badinter, E. (1985). Um amor conquistado: o mito do amor materno (W. Dutra, Trans.). Rio de Janeiro: Nova Fronteira.
Barbosa, P. Z., \& Rocha-Coutinho, M. L. (2007). Maternidade: Novas possibilidades, antigas visões. Psicologia Clínica, 19(1), 163-185.

Bardin, L. (1979). Análise de conteúdo. (L. A. Reto \& A. Pinheiro, Trans.) Lisboa: Edições 70.

Barros, S. S. M., \& Trindade, Z. A. (2007). Maternidade "prematura": Uma investigação psicossociológica na Unidade de Terapia Intensiva Neonatal. Psicologia: Saúde e Doenças, 8(2), 253-269.

Bowby, J. (1990). Apego e perda: a natureza do vínculo: Vol. 2 (A. Cabral, Trans.). São Paulo: Martins Fontes.

Brice, C. W. (1991). What Forever Means: An Empirical Existential-Phenomenological Investigation of Maternal Mourning. Journal of Phenomenological Psychology, 22(1), 16-38.

Bromberg, M. H. P. F. (2000). A psicoterapia em situações de perdas e luto. Campinas: Livro Pleno.

Brougère, G. (1995). Brinquedo e cultura (G. Wajskop, Trans.). São Paulo: Cortez.

Bullington, J., \& Karlsson, G. (1984). Introduction to Phenomenological psychological research. Scandinavian Journal of Psychology, 25, 51-63.

Candau, J. (2008). Memoria e Identidad (E. Rinesi, Trans.). Buenos Aires: Ediciones Del Sol.

Carranza, M. (1994). Saúde reprodutiva da mulher brasileira. In H. I. B. Saffioti, \& M. Muñoz-Vargas (Orgs.), Mulher brasileira é assim (pp. 95-149). Rio de Janeiro: Rosa dos Tempos.

Connerton, P. (1999). Como as sociedades recordam (2 ${ }^{\mathrm{a}}$ ed.) (M. M. Rocha, Trans.). Oeiras: Celta.

Deschamps, J. C., \& Moliner, P. (2009). A identidade em Psicologia Social: dos processos identitários às representações sociais (L. M. E. Orth, Trans.). Petrópolis: Vozes.

Elias, N. (2001). A solidão dos moribundos e envelhecer e morrer (P. Dentzien, Trans.) Rio de Janeiro: Jorge Zahar.

Fentress, J., \& Wickham, C. (1992). Memória Social: novas perspectivas sobre o passado (T. Costa, Trans.). Lisboa: Editorial Teorema.

Franco, M. L. P. B. (2003). Análise de Conteúdo. Brasília: Plano Editora.

Freire, M. C. B. (2006). O som do silêncio: isolamento e sociabilidade no trabalho de luto. Natal: EdUFRN.

Galvão, L. (1999). Saúde sexual e reprodutiva, saúde da mulher e saúde materna: a evolução dos conceitos no mundo e no Brasil. In L. Galvão, \& J. Diaz (Orgs.), Saúde sexual e reprodutiva no Brasil (pp. 165-179). São Paulo: Hucitec.

Giorgi, A. (2008). Sobre o método fenomenológico utilizado como modo de pesquisa qualitativa nas ciências humanas: teoria, prática e avaliação. In V. V. A. A. A pesquisa qualitativa: enfoques epistemológicos e metodológicos (pp. 386-409). Petrópolis: Vozes.

Gomes, W. B. (1998). A entrevista fenomenológica e o estudo da experiência consciente. In W. B. Gomes (Org.), Fenomenologia e Pesquisa em Psicologia (pp. 19-44). Porto Alegre: Editora da Universidade. 
Halbwachs, M. (1990). A memória coletiva (L. L. Schaffter, Trans.). São Paulo: Vértice.

Hrdy, S. B. (2001). Mãe Natureza. Uma visão feminina da evolução: maternidade e seleção natural (A. Cabral, Trans.). Rio de Janeiro: Campus.

Jelin, E. (2001). Los trabajos de la memória. Madri: Siglo XXI.

Kishimoto, T. M., \& Ono, A. T. (2008). Brinquedo, gênero e educação na brinquedoteca. Pro-posições, 19(3), 209-223.

Koury, M. G. P. (2003). Sociologia da emoção: o Brasil urbano sob a ótica do luto. Petrópolis: Vozes.

Laurens, S. (2002). La nostalgie dans l'elaboration des souvenirs. In S. Laurens, \& N. Roussiau (Orgs.), La mémoire sociale: identités et représentations sociales (pp. 259-267). Rennes: Presses Universitaires de Rennes.

Lindemann, E. (1994). The symptomatology and management of acute grief. American Journal of Psychiatry, 151(6), 155-160.

Lorenzi-Cioldi, F. (2002). Les représentations des groupes dominants et dominés: collections et agrégats. Grenoble: PUG.

Lorenzi-Cioldi, F. (2003). A respeito da dominação nas relações entre grupos (J. Alexandre, Trans.). In M. L. Lima, P. Castro, \& M. Garrido (Orgs.), Temas e debates em Psicologia Social (pp. 93-110). Lisboa: Livros Horizonte.

Lowenthal, D. (1998). Como conhecemos o passado (L. Haddad, Trans.). Projeto História, 17, 63-202.

Martins, A. P. V. (2008). "Vamos criar seu filho": os médicos puericultores e a pedagogia materna no Século XX. História, ciências, saúde - Manguinhos, 15(1), 135-154.

Martins, G. (2001). Laços atados: a morte do jovem no discurso materno. Curitiba: Moinho do Verbo.

McCann, W. H. (1941). Nostalgia: a review of the literature. Psychological Bulletin, 38(3), 165-182.

Moreira, J. O., \& Romagnoli, R. C. (2008). Reinventando a maternidade no Programa Mãe Canguru: o encontro com as redes sociais e a singularidade da maternagem. Mnemosine, 4(2), 200-229.

Nascimento, A. R. A., \& Menandro, P. R. M. (2005). Memória social e saudade: especificidades e possibilidades de articulação na análise psicossocial de recordações. Memorandum, 8, 519. Retirado de http://www.fafich.ufmg.br/ memorandum/ artigos08/nascimenan01.htm

Nascimento, A. R. A., \& Rodrigues, M. M. P. (2003). A representação do feminino em manuais do Programa de Agentes Comunitários de Saúde (PACS). In Z. A. Trindade, \& A. N. Andrade (Orgs.), Psicologia e Saúde: um campo em construção (pp. 155-166). São Paulo: Casa do Psicólogo.

Nascimento, A. R. A., Rosa, A. C., \& Barra, M. L. P. (2010). Primaveras e jovens tardes: a memória saudosa da mocidade/juventude na música popular brasileira. Memorandum, 18, 143-160. Retirado de http://www.fafich.ufmg.br/ memoran dum/a18/nascrosba01.pdf
Neder, G. (2008). Ajustando o foco das lentes: um novo olhar sobre a organização das famílias no Brasil. In S. M. Kaloustian (Org.), Família brasileira: a base de tudo (pp. 26-46). São Paulo: Cortez; Brasília: UNICEF.

Olick, J. K., \& Robbins, J. (1998). Social Memory Studies: From Collective Memory to the Historical Sociology of Mnemonic Practices. Annual Review of Sociology, 24, 105-140.

Osório, L.C. (2002). Casais e famílias: uma visão contemporânea. Porto Alegre: Artmed.

Paim, H. H. S. (1998). Marcas no corpo: gravidez e maternidade em grupos populares. In L.F.D. Duarte, \& O. F. Leal. (Orgs), Doença, sofrimento, perturbação: perspectivas etnográficas (pp. 31-47). Rio de Janeiro: Fiocruz.

Parkers, C. M. (1998). Luto: estudos sobre a perda na vida adulta. São Paulo: Summus Editorial.

Pollak, M. (1989). Memória, esquecimento, silêncio (D. R. Flaksman, Trans.). Estudos Históricos, 5(3), 3-15.

Pollak, M. (1992). Memória e Identidade Social (M. Augras, Trans.). Estudos Históricos, 5(10), 200-212.

Rangel, A. P. F. N. R. (2008). Amor Infinito: histórias de pais que perderam seus filhos. São Paulo: Vetor.

Ritivoi, A. D. (2002). Yesterday's self: Nostalgia and the Immigrant Identity. Lanham: Rowman \& Littlefield.

Rocha-Coutinho, M. L. (1994). Tecendo por trás dos panos: a mulher brasileira nas relações familiares. Rio de Janeiro: Rocco.

Rodrigues, G. C. O. (2008). Dilema da maternidade. São Paulo: Annablume.

Rodrigues, M. M. P. (2000). Quem tem mãe tem tudo: os pais e o desenvolvimento de crianças e jovens. In H. A. Novo, \& M. C. S. Menandro (Orgs.), Olhares Diversos: estudando o desenvolvimento humano (pp. 143-156). Vitória: PPGP.

Routledge, C., Arndt, J., Wildschut, T., Sedikides, C., Hart, C. M., Juhl, J., Vingerhoets, A. J., \& Schlotz, W. (2011). The past makes the present meaningful: nostalgia as an existential resource. Journal of Personality and Social Psychology, 101(3), 638-652.

Sá, C. P. (2005). As memórias da memória social. In C. P. Sá (Org.), Memória, imaginário e representações sociais (pp. 6386). Rio de Janeiro: Museu da República.

Sedikides, C., Wildschut, T., Arndt, J., \& Routledge, C. (2008). Nostalgia: Past, Present, and Future. Current Directions in Psychological Science, 17(5), 304-307.

Smith, J. A., \& Eatough, V. (2010). Análise Fenomenológica Interpretativa. In G. Breakwell, C. Fife-Schaw, S. Hammond, \& J. A. Smith (Orgs.), Métodos de pesquisa em Psicologia (F. R. Elizalde, Trans.) (pp. 322-339). Porto Alegre: Artmed.

Starobinski, J. (1966). The Idea of Nostalgia. Diogenes, 14, 81103.

Tajfel, H. (1983). Grupos humanos e categorias sociais: Vol. 2 (L. Amâncio, Trans.). Lisboa: Livros Horizonte. 
Torres, A. R. R., \& Camino, L. (2011). Grupo social, relações intergrupais e identidade social (2011). In L. Camino, A. R. R. Torres, M. E. O. Lima, \& M. E. Pereira (Orgs.), Psicologia Social: Temas e Teorias (pp. 215-239). Brasília: Tecnopolitik.

Trindade, Z. A. (1991). Representações Sociais da Paternidade e da Maternidade: implicações no Processo de Aconselhamento Genético (Tese de Doutorado). Universidade de São Paulo, São Paulo.

Trindade, Z. A., \& Enumo, S. R. F. (2002). Representações Sociais de infertilidade feminina entre mulheres casadas e solteiras. Psicologia: Saúde e Doenças, 2(2), 5-26.

Trindade, Z. A., Menandro, M. C. S., \& Gianordoli-Nascimento, I. F. (2007). Organização e interpretação de entrevistas: uma proposta de procedimento a partir da perspectiva fenomenológica. In M. M. P. Rodrigues, \& P. R. M. Menandro (Orgs.), Lógicas metodológicas: trajetos de pesquisa em psicologia (pp. 71-92). Vitória: GM Gráfica Editora.
Wildschut, T., Sedikides, C., Arndt, J., \& Routledge, C. (2006). Nostalgia: Content, Triggers, Functions. Journal of Personality and Social Psychology, 91(5), 975-993.

Worchel, S., \& Coutant, D. (2004). It Takes Two to Tango: Relating Group Identity to Individual Identity within the Framework of Group Development. In M. B. Brener, \& M. Hewstone (Orgs.), Self and social identity (pp. 182-202). Oxford: Blackwell.

Zhou, X., Sedikides, C., Wildschut, T., \& Gao, D. G. (2008). Counteracting loneliness: on the restorative function of nostalgia. Psychological Science, 19, 1023-1029.

Recebido em 06/08/2012 Primeira Decisão Editorial em 30/03/2014 Aceito em 09/04/2014 